OPEN ACCESS

Edited by:

Jagadeesh Bayry,

Indian Institute of Technology

Palakkad, India

Reviewed by:

Paola de Candia,

MultiMedica (IRCCS), Italy

Marit Inngjerdingen,

University of Oslo, Norway

*Correspondence:

Hiroyuki Oshium

oshiumi@kumamoto-u.ac.jp

Specialty section:

This article was submitted to

Molecular Innate Immunity,

a section of the journal

Frontiers in Immunology

Received: 25 March 2021

Accepted: 31 May 2021

Published: 15 June 2021

Citation:

Oshiumi H (2021) Circulating

Extracellular Vesicles Carry

Immune Regulatory miRNAs and Regulate Vaccine

Efficacy and Local

Inflammatory Response

After Vaccination.

Front. Immunol. 12:685344. doi: 10.3389/fimmu.2021.685344

\section{Circulating Extracellular Vesicles Carry Immune Regulatory miRNAs and Regulate Vaccine Efficacy and Local Inflammatory Response After Vaccination}

\section{Hiroyuki Oshiumi ${ }^{*}$}

Department of Immunology, Graduate School of Medical Sciences, Faculty of Life Sciences, Kumamoto University, Kumamoto, Japan

Vaccination is the best prophylaxis for the prevention of infectious diseases, including coronavirus disease 2019. However, the efficacy of vaccines and onset of adverse reactions vary among individuals. Circulating extracellular vesicles (EVs) regulate the immune responses after vaccination by delivering microRNAs (miRNAs) to myeloid and lymphoid cells. Among these, miR-192 levels in serum EVs increase with aging, in an IL-6dependent manner, reducing excessive IL-6 expression in aged mice, creating a negative feedback loop. Excessive IL-6 expression reduces vaccination efficacy in aged mice, while EV miR-192 improves efficacy in these aged mice as well, making this miRNA an interesting focus of study. miR-21 levels in serum EVs also increase with aging, and regulates the expression of IL-12 required for Th1 responses; therefore, EV miR-21 is expected to regulate vaccine efficacy. miR-451a, another important miRNA, is abundant in serum EVs and controls the expression of cytokines, such as type I interferon and IL-6. However, levels differ among individuals and correlate with local inflammatory symptoms experienced after a seasonal flu vaccination. These findings suggest the importance of EV miRNAs as a tool to improve vaccine efficacy and also as biomarkers to predict the immune response and adverse reactions after vaccinations.

Keywords: microRNA, vaccine, extracellular vesicle, innate immunity, cytokine

\section{INTRODUCTION}

Vaccines are the best prophylaxis for infectious disease prevention, including seasonal flu and coronavirus disease 2019 (COVID-19) (1,2). Vaccines comprise specific antigens and adjuvants (3); several types of adjuvants, such as aluminum salts and monophosphoryl lipid A, are used in vaccines $(4,5)$. These induce pro-inflammatory cytokine expression, and activate dendritic cells and macrophages, leading to the priming of naïve $\mathrm{T}$ cells and provoking antigen-specific immune responses, including B-cell activation and antibody production (3). In addition to artificial compounds, components of viral particles also function as adjuvants, e.g., in the inactivated wholevirus influenza vaccine. Viral RNA within its viral particles that are recognized by Toll-like receptors 
determine the efficiency of vaccines (6); thus, adjuvant-induced innate immune responses are crucial for vaccine efficacy.

Studies have revealed that several microRNAs (miRNAs) regulate the innate immune responses (7-10). miRNAs are delivered from the host to donor cells by extracellular vesicles (EVs), such as exosomes and microvesicles (11-13). Exosomes are small vesicles, approximately $100 \mathrm{~nm}$ in diameter that express CD9, CD63, and CD81 proteins $(14,15)$, while microvesicles are $>100 \mathrm{~nm}$ in diameter $(14,16)$. Several miRNAs within EVs affect immune responses after vaccination.

\section{EV MIR-192 IMPROVES AGE-ASSOCIATED DECREASES IN VACCINE EFFICACY}

Aging affect the immune system $(17,18)$, and the efficacy of vaccines decreases with age (19). It is expected that aging would lead to immune dysfunction because of impaired B cell generation, a reduction in naïve $\mathrm{T}$ cells, a decreased ability of hematopoietic stem cells to replicate, and/or some other phenomena associated with age $(20,21)$. However, several studies have shown that chronic inflammatory responses increase with age, thereby decreasing vaccination efficacy (17, 22-24). For example, excessive TNF- $\alpha$ down-regulates CD28 expression on T cells (25), and high TNF- $\alpha$ levels lead to reduced $\mathrm{B}$ cell responses (26). These former studies suggest that excessive inflammation diminishes vaccine efficacy (27).

Decreased vaccine efficacy with aging has been observed in mouse animal models; mice aged 8-12 weeks are usually used for immune response analyses, and older mice, (1> year), exhibit lower vaccination efficacy than young mice $(22,28)$.

miR-192 is a miRNA induced by $\mathrm{p} 53$ that improves renal fibrosis in diabetic nephropathy patients $(29,30)$ and plays a role in several other diseases $(31,32)$. Recently, we found that miR192 was an aging-associated miRNA and that EVs delivered miR-192 to macrophages, thereby reducing pro-inflammatory cytokine expression in the lungs (22). miR-192 targets ZEB2, MIP2 $\alpha$, TRIM25, IL-17RA, and Rictor mRNAs (Table 1): MIP2 $\alpha$ is a chemokine that recruits neutrophils; TRIM25 is required for pro-inflammatory cytokine expression in response to influenza A virus RNAs $(45,46)$; and IL-17RA is crucial for pro-inflammatory cytokine expression in response to IL-17 (47).

TABLE 1 | Immune regulatory miRNAs and their targets.

\begin{tabular}{|c|c|c|}
\hline miRNA & Target & Reference \\
\hline \multirow[t]{5}{*}{ miR-192 } & ZEB2 & $(30,33)$ \\
\hline & MIP2 $\alpha$ (CXCL2) & (34) \\
\hline & TRIM25 & (35) \\
\hline & IL-17RA & (36) \\
\hline & Rictor & (37) \\
\hline \multirow[t]{3}{*}{ miR-21 } & IL-12p35 & (38) \\
\hline & PDCD4 & (39) \\
\hline & PTEN & (40) \\
\hline \multirow[t]{3}{*}{ miR-451 } & $14-3-3 \zeta$ & $(41,42)$ \\
\hline & CAB39 & (43) \\
\hline & $\mid \mathrm{KK}-\beta$ & (44) \\
\hline
\end{tabular}

These targets might be involved in miR-192-mediated suppression of pro-inflammatory cytokine expression.

Additionally, we found that the expression of proinflammatory cytokines in the lung was prolonged in aged mice after intranasal administration of a whole-virus influenza vaccine (22). However, intranasal administration of EVs containing miR192 mimic RNA reduced excessive pro-inflammatory cytokine expression, such as IL-6, and improved antigen-specific antibody levels after vaccination in aged mice (22). Since EV miR-192 levels increased in aged mice in an IL-6-dependent manner (22), it was expected that miR-192 would constitute a negative feedback loop to attenuate chronic inflammatory responses, resulting in improved immune responses and improved vaccination efficacy in elderly (Figure 1) (22).

\section{MIR-21 REGULATES IMMUNE RESPONSES AFTER VACCINATION}

Serum IL-6 levels increase with aging in humans and mice (48), and miR-19b, miR-21, miR-181c, and miR-322 levels in serum EVs also increase with aging in an IL-6-dependent manner (22). Among those aging-associated miRNAs, miR-21 is known to regulate the immune responses following vaccination.

miR-21 negatively regulates the expression of IL-12p35, as well as IL-6, IL-8, TNF- $\alpha$, and IL-1 $\beta(38,49,50)$. Although a contradicting report has shown the miR-21-augmented pro-inflammatory cytokine expression of IL-1 $\beta$ and IL- 6 in RAW264.7 cells (51), Knockout (KO) studies have shown that miR-21 KO also increased the expression of these proinflammatory cytokines as well $(52,53)$. Therefore, EV miR-21 is expected to attenuate the expression of these pro-inflammatory cytokines (Figure 1). miR-21 targets mRNAs of IL-12p35, PDCD4, and PTEN (Table 1): although PDCD4 promotes pro-inflammatory cytokine expression (54), PTEN reduces pro-inflammatory cytokine expression (40), and these mechanisms might underlie the apparent contradictions.

miR-21 levels affect the efficacy of a live-attenuated vaccine of Leishmania, $\mathrm{LdCen}^{-/-}$(55). IL-12 is an essential cytokine for Th1 response to Leishmania; therefore, miR-21 decreased Th1 immunity, thereby affecting the efficacy of this live-attenuated vaccine (55). Interestingly, miR-21-containing exosomes derived from dendritic cells regulate $\mathrm{CD} 4^{+} \mathrm{T}$ cell proliferation (56); thus, it is expected that serum EV miR-21 levels would affect innate and adaptive immune responses following vaccination. Further investigation is required to determine the role of EV miR-21 in the immune response after vaccination.

\section{MIRNA-451A IS ASSOCIATED WITH LOCAL INFLAMMATORY RESPONSES AFTER VACCINATION}

Innate immunity itself is required to initiate the adaptive immune responses, whereas it leads to a local inflammatory 


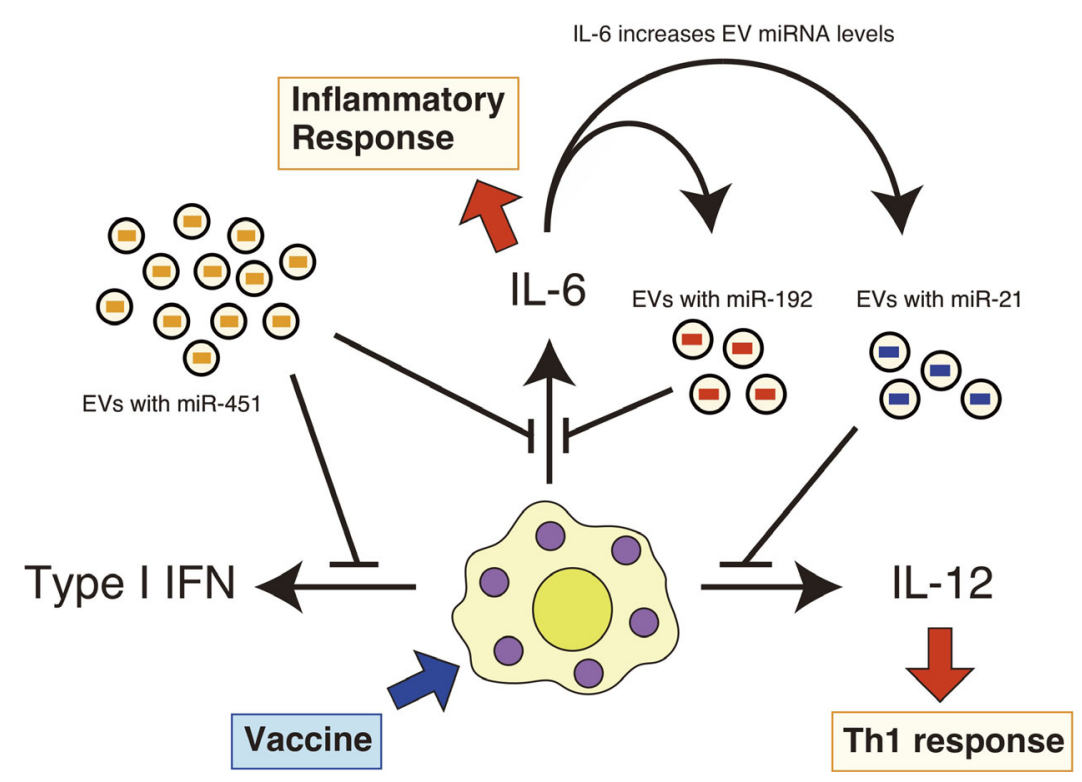

FIGURE 1 | EV miRNAs regulate cytokine expression in response to vaccines. EVs deliver miR-451a, miR-192, and miR-21 to recipient cells, such as macrophages. Vaccine adjuvants then stimulate these macrophages and dendritic cells, resulting in the production of pro-inflammatory cytokines. miR-451a attenuates type I IFN and IL-6 expression in macrophages, and miR-192 reduces the expression of IL-6. miR-21 has the ability to attenuate the IL-12 expression. miR-192 and miR-21 levels in EVs increase with aging in an IL-6-dependent manner. Serum IL-6 levels are increased with aging, and thus constituting a miR-192-dependen negative feedback loop.

response. Upon stimulation from adjuvants, IL-6, TNF- $\alpha$, and IL-1 $\beta$ are produced from macrophages and increase vascular permeability, allowing the flow of red and white blood cells as well as plasma with small molecules, resulting in local swelling, pain, and redness (57-60). Additionally, circulation of these cytokines in the blood flow causes prostaglandin E2 (PGE2) production in the hypothalamus, leading to fever (61). Excessive innate immune responses are harmful to the host: hypermorphic mutations in the genes involved in innate immune responses cause autoimmune disorders (62).

miR-451a attenuates pro-inflammatory cytokine expression (41), as it targets 14-3-3 (Table 1), which controls the activities of FOXO3 and ZFP36 (41). FOXO3 is an inhibitory transcription factor for cytokine expression (63), and ZFP36 can bind to AUrich elements of the untranslated mRNA regions, thus destabilizing cytokine mRNAs (41). In addition to $14-3-3 \zeta$, IKK- $\beta$ and CAB39 are also targeted by miR-451a (Table 1): IKK- $\beta$ plays a crucial role in NF- $\kappa B$ activation (64). These mechanisms are expected to underlie miR-451a-mediated suppression of pro-inflammatory cytokine expression.

miR-451a is efficiently sorted into EVs in several cell types $(65,66)$; therefore, miR-451a levels in serum EVs are very high $(67,68)$, and its intracellular levels are relatively low $(65,69)$. We found that EV miR-451a levels in the serum of a culture medium correlated with intracellular miR-451a levels, a few days after incubation of macrophages with a serum-containing medium, because EVs deliver miR-451a to macrophages (69). Therefore, EVs miR-451a levels in serum of culture medium correlated with expression levels of cytokines, such as type I IFN and IL-6, in macrophages stimulated with influenza A virus vaccines (69). This correlation was also observed in several other miRNAs (69).

In the short term, miR-451a levels in human sera are relatively stable, with few changes of more than two-fold in a week (69); however, levels gradually fluctuate and, in some cases, change by more than 10-fold during a year (69). IL-6 is a pro-inflammatory cytokine regulated by miR-451a that causes inflammatory responses, including vesicular permeability (41). Our clinical study showed that miR-451a levels in serum EVs before vaccination correlated with the occurrence of local inflammatory symptoms observed after a seasonal flu vaccination (68). Several other EV miRNAs were also associated with local inflammatory responses (68). Christian LM et al. have reported the correlation of local inflammatory symptoms with the expression of pro-inflammatory cytokines after vaccination (70). These observations imply that circulating EV miRNAs regulate local cytokine expression and inflammatory responses after vaccination. However, it is still possible that the levels of miR451a and other immune regulatory miRNA reflect a physical condition that affects the inflammatory responses. Further studies are required to determine mechanism underlying the correlation between miR-451a levels in circulating EVs and immune responses after vaccination.

\section{DISCUSSION}

Vaccine efficacy varies among individuals, and vaccine-related adverse reactions occur only in certain cases. Environmental 
factors affect immune responses $(71,72)$ and are expected to cause differences in vaccine efficacy and the onset of adverse reactions. Increasing evidence has shown that circulating EV miRNAs affect immune responses after vaccination, and miRNA levels vary among healthy individuals. For example, excessive glucose uptakes and several diseases are reported to affect miR-451a levels (73-76). Some of the environmental factors that affect EV miRNA levels might regulate vaccine-induced immune responses; hence, studies of the environmental factors affecting circulating EV miRNA levels are important in identifying environmental factors affecting immune responses after vaccination.

Recent studies have identified the significant potential of serum miRNAs as biomarkers for cancer, diabetes, Alzheimer's disease, allergic inflammatory disease, rheumatoid arthritis, etc. (77-80). Thus, since serum EV miRNAs affect the immune responses following vaccination, they can potentially be used as biomarkers to predict vaccine efficacy and adverse reactions. Similarly, if a vaccination is predicted to be ineffective for a person, improvement of the efficacy by an additional vaccination is possible. In the case of the recent COVID-19 outbreak, herd immunity will be crucial in eradicating the pandemic (81). Thus, prediction of the efficacy and follow-up vaccination requirements might help achieve effective herd immunity against COVID-19 efficiently. COVID-19 vaccination is progressing all over the world and, thus cohort studies investigating the association of $\mathrm{EV}$ miRNAs with antibody production or memory cell generation after vaccination would reveal the potential of EV miRNAs as biomarkers.

Vaccination efficacy decreases with age, therefore, miRNAs that affect or improve immune responses of the elderly would also help improve the vaccination efficacy. Indeed, miR-192 in EVs improves the efficacy of vaccination in aged mice. Recent approaches have tested the engineering of exosomes for delivering therapeutic proteins and nucleic acids, as well as miRNAs (82). Thus, it is expected that vaccines containing EV miR-192 would be useful for vaccinating the elderly. In addition

\section{REFERENCES}

1. Shin MD, Shukla S, Chung YH, Beiss V, Chan SK, Ortega-Rivera OA, et al. Covid-19 Vaccine Development and a Potential Nanomaterial Path Forward. Nat Nanotechnol (2020) 15:646-55. doi: 10.1038/s41565-020-0737-y

2. Corbett KS, Flynn B, Foulds KE, Francica JR, Boyoglu-Barnum S, Werner AP, et al. Evaluation of the Mrna-1273 Vaccine Against SARS-CoV-2 in Nonhuman Primates. N Engl J Med (2020) 383:1544-55. doi: 10.1056/ NEJMoa2024671

3. Coffman RL, Sher A, Seder RA. Vaccine Adjuvants: Putting Innate Immunity to Work. Immunity (2010) 33:492-503. doi: 10.1016/ j.immuni.2010.10.002

4. Mata-Haro V, Cekic C, Martin M, Chilton PM, Casella CR, Mitchell TC. The Vaccine Adjuvant Monophosphoryl Lipid A as a TRIF-biased Agonist of TLR4. Science (2007) 316:1628-32. doi: 10.1126/science.1138963

5. Temizoz B, Kuroda E, Ishii KJ. Vaccine Adjuvants as Potential Cancer Immunotherapeutics. Int Immunol (2016) 28:329-38. doi: 10.1093/intimm/ dxw015

6. Koyama S, Aoshi T, Tanimoto T, Kumagai Y, Kobiyama K, Tougan T, et al. Plasmacytoid Dendritic Cells Delineate Immunogenicity of Influenza Vaccine Subtypes. Sci Trans Med (2010) 2:25ra4. doi: 10.1126/scitranslmed.3000759 to $\mathrm{miR}-192$, miR-451a could improve vaccines. miR-451a levels in EVs were negatively correlated with inflammatory responses at the vaccination site and reduced pro-inflammatory cytokine expression $(68,69)$; therefore, the addition of EV miR-45 to a vaccine might improve excessive inflammatory symptoms, such as pain, swelling, and redness, without reducing efficacy. EVs containing immune regulatory miRNAs could be useful tools to improve vaccine efficacy and to reduce adverse reactions.

Although both exosomes and microvesicles deliver miRNAs, there are functional differences between them; for example, miR150 is efficiently sorted into exosomes but not microvesicles (83). Furthermore, EVs can be classified into several types, and each type contains distinct components (84). It is therefore possible that specific EVs affect the immune response after vaccination. Further studies are required to reveal the role of EVs in regulating immune responses after vaccination.

\section{AUTHOR CONTRIBUTIONS}

The author confirms being the sole contributor of this work and has approved it for publication.

\section{FUNDING}

This work was supported in part by Grants-in-Aid from the Japan Agency for Medical Research Development (AMED) and Society of the Promotion of Sciences (JSPS).

\section{ACKNOWLEDGMENTS}

I thank all my laboratory members for helpful discussion and Enago for English language editing.

7. Yang Y, Liu D, Xi Y, Li J, Liu B, Li J. Upregulation of miRNA-140-5p Inhibits Inflammatory Cytokines in Acute Lung Injury Through the MyD88/NFkappaB Signaling Pathway by Targeting TLR4. Exp Ther Med (2018) 16:391320. doi: $10.3892 /$ etm.2018.6692

8. Fukushima Y, Okamoto M, Ishikawa K, Kouwaki T, Tsukamoto H, Oshiumi H. Activation of TLR3 and Its Adaptor TICAM-1 Increases miR-21 Levels in Extracellular Vesicles Released From Human Cells. Biochem Biophys Res Commun (2018) 500:744-50. doi: 10.1016/j.bbrc.2018.04.146

9. Bala S, Petrasek J, Mundkur S, Catalano D, Levin I, Ward J, et al. Circulating microRNAs in Exosomes Indicate Hepatocyte Injury and Inflammation in Alcoholic, Drug-Induced, and Inflammatory Liver Diseases. Hepatology (2012) 56:1946-57. doi: 10.1002/hep.25873

10. Alexander M, Hu R, Runtsch MC, Kagele DA, Mosbruger TL, Tolmachova T, et al. Exosome-Delivered microRNAs Modulate the Inflammatory Response to Endotoxin. Nat Commun (2015) 6:7321. doi: 10.1038/ncomms8321

11. Colombo M, Raposo G, Thery C. Biogenesis, Secretion, and Intercellular Interactions of Exosomes and Other Extracellular Vesicles. Annu Rev Cell Dev Biol (2014) 30:255-89. doi: 10.1146/annurev-cellbio-101512-122326

12. Hulsmans M, Holvoet P. MicroRNA-containing Microvesicles Regulating Inflammation in Association With Atherosclerotic Disease. Cardiovasc Res (2013) 100:7-18. doi: 10.1093/cvr/cvt161 
13. Montecalvo A, Larregina AT, Shufesky WJ, Stolz DB, Sullivan ML, Karlsson JM, et al. Mechanism of Transfer of Functional microRNAs Between Mouse Dendritic Cells via Exosomes. Blood (2012) 119:756-66. doi: 10.1182/blood2011-02-338004

14. Kouwaki T, Okamoto M, Tsukamoto H, Fukushima Y, Oshiumi H. Extracellular Vesicles Deliver Host and Virus RNA and Regulate Innate Immune Response. Int J Mol Sci (2017) 18:666. doi: 10.3390/ijms18030666

15. Valadi H, Ekstrom K, Bossios A, Sjostrand M, Lee JJ, Lotvall JO. ExosomeMediated Transfer of mRNAs and microRNAs Is a Novel Mechanism of Genetic Exchange Between Cells. Nat Cell Biol (2007) 9:654-9. doi: 10.1038/ ncb1596

16. Lawson C, Vicencio JM, Yellon DM, Davidson SM. Microvesicles and Exosomes: New Players in Metabolic and Cardiovascular Disease. J Endocrinol (2016) 228:R57-71. doi: 10.1530/JOE-15-0201

17. Ferrucci L, Fabbri E. Inflammageing: Chronic Inflammation in Ageing, Cardiovascular Disease, and Frailty. Nat Rev Cardiol (2018) 15:505-22. doi: 10.1038/s41569-018-0064-2

18. Shaw AC, Goldstein DR, Montgomery RR. Age-Dependent Dysregulation of Innate Immunity. Nat Rev Immunol (2013) 13:875-87. doi: 10.1038/nri3547

19. Dugan HL, Henry C, Wilson PC. Aging and Influenza Vaccine-Induced Immunity. Cell Immunol (2020) 348:103998. doi: 10.1016/j.cellimm.2019.103998

20. Boehm T, Swann JB. Thymus Involution and Regeneration: Two Sides of the Same Coin? Nat Rev Immunol (2013) 13:831-8. doi: 10.1038/nri3534

21. Linton PJ, Dorshkind K. Age-Related Changes in Lymphocyte Development and Function. Nat Immunol (2004) 5:133-9. doi: 10.1038/ni1033

22. Tsukamoto H, Kouwaki T, Oshiumi H. Aging-Associated Extracellular Vesicles Contain Immune Regulatory Micrornas Alleviating Hyperinflammatory State and Immune Dysfunction in the Elderly. iScience (2020) 23:101520. doi: 10.1016/j.isci.2020.101520

23. Pinti M, Appay V, Campisi J, Frasca D, Fulop T, Sauce D, et al. Aging of the Immune System: Focus on Inflammation and Vaccination. Eur J Immunol (2016) 46:2286-301. doi: 10.1002/eji.201546178

24. Franceschi C, Bonafe M, Valensin S, Olivieri F, De Luca M, Ottaviani E, et al. Inflamm-Aging. An Evolutionary Perspective on Immunosenescence. Ann N Y Acad Sci (2000) 908:244-54. doi: 10.1111/j.1749-6632.2000. tb06651.x

25. Bryl E, Vallejo AN, Matteson EL, Witkowski JM, Weyand CM, Goronzy JJ. Modulation of CD28 Expression With Anti-Tumor Necrosis Factor Alpha Therapy in Rheumatoid Arthritis. Arthritis Rheum (2005) 52:2996-3003. doi: 10.1002/art.21353

26. Frasca D, Diaz A, Romero M, Landin AM, Blomberg BB. High TNF-Alpha Levels in Resting B Cells Negatively Correlate With Their Response. Exp Gerontol (2014) 54:116-22. doi: 10.1016/j.exger.2014.01.004

27. Frasca D, Blomberg BB. Inflammaging Decreases Adaptive and Innate Immune Responses in Mice and Humans. Biogerontology (2016) 17:7-19. doi: 10.1007/s10522-015-9578-8

28. Ramirez A, Co M, Mathew A. Cpg Improves Influenza Vaccine Efficacy in Young Adult But Not Aged Mice. PloS One (2016) 11:e0150425. doi: 10.1371/ journal.pone.0150425

29. Chen J, Wang J, Li H, Wang S, Xiang X, Zhang D. p53 Activates miR-192-5p to Mediate Vancomycin Induced AKI. Sci Rep (2016) 6:38868. doi: 10.1038/ srep38868

30. Deshpande SD, Putta S, Wang M, Lai JY, Bitzer M, Nelson RG, et al. Transforming Growth Factor-Beta-Induced Cross Talk Between p53 and a microRNA in the Pathogenesis of Diabetic Nephropathy. Diabetes (2013) 62:3151-62. doi: 10.2337/db13-0305

31. Zhang X, Peng Y, Yuan Y, Gao Y, Hu F, Wang J, et al. Histone Methyltransferase SET8 Is Regulated by miR-192/215 and Induces Oncogene-Induced Senescence Via P53-Dependent DNA Damage in Human Gastric Carcinoma Cells. Cell Death Dis (2020) 11:937. doi: 10.1038/s41419-020-03130-4

32. Xu J, Zou J, Wu L, Lu W. Transcriptome Analysis Uncovers the Diagnostic Value of miR-192-5p/HNF1A-AS1/VIL1 Panel in Cervical Adenocarcinoma. Sci Rep (2020) 10:16584. doi: 10.1038/s41598-020-73523-0

33. Kim T, Veronese A, Pichiorri F, Lee TJ, Jeon YJ, Volinia S, et al. p53 Regulates Epithelial-Mesenchymal Transition Through microRNAs Targeting ZEB1 and ZEB2. J Exp Med (2011) 208:875-83. doi: 10.1084/jem.20110235

34. Wu F, Zikusoka M, Trindade A, Dassopoulos T, Harris ML, Bayless TM, et al. MicroRNAs Are Differentially Expressed in Ulcerative Colitis and Alter
Expression of Macrophage Inflammatory Peptide-2 Alpha. Gastroenterology (2008) 135:1624-35.e24. doi: 10.1053/j.gastro.2008.07.068

35. Wang J, Yin G, Bian H, Yang J, Zhou P, Yan K, et al. Lncrna XIST Upregulates TRIM25 via Negatively Regulating miR-192 in Hepatitis B Virus-Related Hepatocellular Carcinoma. Mol Med (2021) 27:41. doi: 10.1186/s10020-02100278-3

36. Li Y, Zhang J, Shi J, Liu K, Wang X, Jia Y, et al. Exosomes Derived From Human Adipose Mesenchymal Stem Cells Attenuate Hypertrophic Scar Fibrosis by miR-192-5p/IL-17RA/Smad Axis. Stem Cell Res Ther (2021) 12:221. doi: 10.1186/s13287-021-02290-0

37. Liu XL, Pan Q, Cao HX, Xin FZ, Zhao ZH, Yang RX, et al. Lipotoxic Hepatocyte-Derived Exosomal MicroRNA 192-5p Activates Macrophages Through Rictor/Akt/Forkhead Box Transcription Factor O1 Signaling in Nonalcoholic Fatty Liver Disease. Hepatology (2020) 72:454-69. doi: 10.1002/hep. 31050

38. Lu TX, Munitz A, Rothenberg ME. MicroRNA-21 is Up-Regulated in Allergic Airway Inflammation and Regulates IL-12p35 Expression. J Immunol (2009) 182:4994-5002. doi: 10.4049/jimmunol.0803560

39. Sheedy FJ, Palsson-McDermott E, Hennessy EJ, Martin C, O’Leary JJ, Ruan Q, et al. Negative Regulation of TLR4 via Targeting of the Proinflammatory Tumor Suppressor PDCD4 by the microRNA Mir-21. Nat Immunol (2010) 11:141-7. doi: 10.1038/ni.1828

40. Iliopoulos D, Jaeger SA, Hirsch HA, Bulyk ML, Struhl K. STAT3 Activation of miR-21 and miR-181b-1 via PTEN and CYLD Are Part of the Epigenetic Switch Linking Inflammation to Cancer. Mol Cell (2010) 39:493-506. doi: 10.1016/j.molcel.2010.07.023

41. Rosenberger CM, Podyminogin RL, Navarro G, Zhao GW, Askovich PS, Weiss MJ, et al. miR-451 Regulates Dendritic Cell Cytokine Responses to Influenza Infection. J Immunol (2012) 189:5965-75. doi: 10.4049/ jimmunol.1201437

42. Patrick DM, Zhang CC, Tao Y, Yao H, Qi X, Schwartz RJ, et al. Defective Erythroid Differentiation in miR-451 Mutant Mice Mediated by 14-3-3zeta. Genes Dev (2010) 24:1614-9. doi: 10.1101/gad.1942810

43. Godlewski J, Nowicki MO, Bronisz A, Nuovo G, Palatini J, De Lay M, et al. MicroRNA-451 Regulates LKB1/AMPK Signaling and Allows Adaptation to Metabolic Stress in Glioma Cells. Mol Cell (2010) 37:620-32. doi: 10.1016/ j.molcel.2010.02.018

44. Li HP, Zeng XC, Zhang B, Long JT, Zhou B, Tan GS, et al. miR-451 Inhibits Cell Proliferation in Human Hepatocellular Carcinoma Through Direct Suppression of IKK-Beta. Carcinogenesis (2013) 34:2443-51. doi: 10.1093/ carcin/bgt206

45. Li MM, Lau Z, Cheung P, Aguilar EG, Schneider WM, Bozzacco L, et al. Trim25 Enhances the Antiviral Action of Zinc-Finger Antiviral Protein (Zap). PloS Pathog (2017) 13:e1006145. doi: 10.1371/journal.ppat.1006145

46. Gack MU, Albrecht RA, Urano T, Inn KS, Huang IC, Carnero E, et al. Influenza A Virus NS1 Targets the Ubiquitin Ligase TRIM25 to Evade Recognition by the Host Viral RNA Sensor RIG-I. Cell Host Microbe (2009) 5:439-49. doi: 10.1016/j.chom.2009.04.006

47. Goepfert A, Lehmann S, Blank J, Kolbinger F, Rondeau JM. Structural Analysis Reveals That the Cytokine Il-17f Forms a Homodimeric Complex With Receptor Il-17RC to Drive Il-17ra-Independent Signaling. Immunity (2020) 52:499-512.e5. doi: 10.1016/j.immuni.2020.02.004

48. Daynes RA, Araneo BA, Ershler WB, Maloney C, Li GZ, Ryu SY. Altered Regulation of IL-6 Production With Normal Aging. Possible Linkage to the Age-Associated Decline in Dehydroepiandrosterone and Its Sulfated Derivative. I Immunol (1993) 150:5219-30.

49. Lu TX, Hartner J, Lim EJ, Fabry V, Mingler MK, Cole ET, et al. MicroRNA-21 Limits In Vivo Immune Response-Mediated Activation of the IL-12/IFN-gamma Pathway, Th1 Polarization, and the Severity of Delayed-Type Hypersensitivity. J Immunol (2011) 187:3362-73. doi: 10.4049/jimmunol.1101235

50. Gao X, Huang X, Yang Q, Zhang S, Yan Z, Luo R, et al. MicroRNA-21-5p Targets PDCD4 to Modulate Apoptosis and Inflammatory Response to Clostridium Perfringens Beta2 Toxin Infection in IPEC-J2 Cells. Dev Comp Immunol (2021) 114:103849. doi: 10.1016/j.dci.2020.103849

51. Madhyastha R, Madhyastha H, Nurrahmah QI, Purbasari B, Maruyama M, Nakajima Y. MicroRNA 21 Elicits a Pro-inflammatory Response in Macrophages, With Exosomes Functioning as Delivery Vehicles. Inflammation (2021). doi: $10.1007 /$ s10753-021-01415-0 
52. Zhou W, Su L, Duan X, Chen X, Hays A, Upadhyayula S, et al. MicroRNA-21 Down-Regulates Inflammation and Inhibits Periodontitis. Mol Immunol (2018) 101:608-14. doi: 10.1016/j.molimm.2018.05.008

53. Yang L, Wang B, Zhou Q, Wang Y, Liu X, Liu Z, et al. MicroRNA-21 Prevents Excessive Inflammation and Cardiac Dysfunction After Myocardial Infarction Through Targeting KBTBD7. Cell Death Dis (2018) 9:769. doi: 10.1038/ s41419-018-0805-5

54. Qiu X, Dong S, Qiao F, Lu S, Song Y, Lao Y, et al. Hbx-Mediated miR-21 Upregulation Represses Tumor-Suppressor Function of PDCD4 in Hepatocellular Carcinoma. Oncogene (2013) 32:3296-305. doi: 10.1038/ onc. 2013.150

55. Gannavaram S, Bhattacharya P, Siddiqui A, Ismail N, Madhavan S, Nakhasi HL. Mir-21 Expression Determines the Early Vaccine Immunity Induced by LdCen (-/-) Immunization. Front Immunol (2019) 10:2273. doi: 10.3389/ fimmu.2019.02273

56. Ji Q, Liu J, Dong Y, Wang L, Dong K, Setiz B, et al. Exosomes Derived From Thymic Stromal Lymphopoietin-Treated Dendritic Cells Regulate T Helper 17/Regulatory T Cell Differentiation Via miR-21/Smad7 Axis. Exp Cell Res (2021) 398:112393. doi: 10.1016/j.yexcr.2020.112393

57. Vandenbroucke E, Mehta D, Minshall R, Malik AB. Regulation of Endothelial Junctional Permeability. Ann N Y Acad Sci (2008) 1123:134-45. doi: 10.1196/ annals. 1420.016

58. Dinarello CA. Infection, Fever, and Exogenous and Endogenous Pyrogens: Some Concepts Have Changed. J Endotoxin Res (2004) 10:201-22. doi: $10.1179 / 096805104225006129$

59. Dinarello CA. Cytokines as Endogenous Pyrogens. J Infect Dis (1999) 179 Suppl 2:S294-304. doi: 10.1086/513856

60. Kawabata A. Prostaglandin E2 and Pain-an Update. Biol Pharm Bull (2011) 34:1170-3. doi: 10.1248/bpb.34.1170

61. Lazarus M, Yoshida K, Coppari R, Bass CE, Mochizuki T, Lowell BB, et al. EP3 Prostaglandin Receptors in the Median Preoptic Nucleus are Critical for Fever Responses. Nat Neurosci (2007) 10:1131-3. doi: 10.1038/nn1949

62. Kato H, Fujita T. Autoimmunity Caused by Constitutive Activation of Cytoplasmic Viral RNA Sensors. Cytokine Growth Factor Rev (2014) 25:739-43. doi: 10.1016/j.cytogfr.2014.08.003

63. Luron L, Saliba D, Blazek K, Lanfrancotti A, Udalova IA. FOXO3 as a New IKK-epsilon-controlled Check-Point of Regulation of IFN-beta Expression. Eur J Immunol (2012) 42:1030-7. doi: 10.1002/eji.201141969

64. Arkan MC, Hevener AL, Greten FR, Maeda S, Li ZW, Long JM, et al. IKK-Beta Links Inflammation to Obesity-Induced Insulin Resistance. Nat Med (2005) 11:191-8. doi: 10.1038/nm1185

65. Villarroya-Beltri C, Gutierrez-Vazquez C, Sanchez-Cabo F, Perez-Hernandez D, Vazquez J, Martin-Cofreces N, et al. Sumoylated hnRNPA2B1 Controls the Sorting of miRNAs Into Exosomes Through Binding to Specific Motifs. Nat Commun (2013) 4:2980. doi: 10.1038/ncomms3980

66. Cha DJ, Franklin JL, Dou Y, Liu Q, Higginbotham JN, Demory Beckler M, et al. KRAS-Dependent Sorting of miRNA to Exosomes. eLife (2015) 4: e07197. doi: 10.7554/eLife.07197

67. Santangelo L, Giurato G, Cicchini C, Montaldo C, Mancone C, Tarallo R, et al. The RNA-Binding Protein SYNCRIP is a Component of the Hepatocyte Exosomal Machinery Controlling MicroRNA Sorting. Cell Rep (2016) 17:799808. doi: 10.1016/j.celrep.2016.09.031

68. Miyashita Y, Ishikawa K, Fukushima Y, Kouwaki T, Nakamura K, Oshiumi H. Immune-Regulatory microRNA Expression Levels Within Circulating Extracellular Vesicles Correspond With the Appearance of Local Symptoms After Seasonal Flu Vaccination. PloS One (2019) 14:e0219510. doi: 10.1371/ journal.pone.0219510

69. Okamoto M, Fukushima Y, Kouwaki T, Daito T, Kohara M, Kida H, et al. MicroRNA-451a in Extracellular, Blood-Resident Vesicles Attenuates Macrophage and Dendritic Cell Responses to Influenza Whole-Virus Vaccine. J Biol Chem (2018) 293:18585-600. doi: 10.1074/jbc.RA118.003862
70. Christian LM, Porter K, Karlsson E, Schultz-Cherry S. Proinflammatory Cytokine Responses Correspond With Subjective Side Effects After Influenza Virus Vaccination. Vaccine (2015) 33:3360-6. doi: 10.1016/ j.vaccine.2015.05.008

71. Aguirre-Gamboa R, Joosten I, Urbano PCM, van der Molen RG, van Rijssen E, van Cranenbroek B, et al. Differential Effects of Environmental and Genetic Factors on T and B Cell Immune Traits. Cell Rep (2016) 17:2474-87. doi: 10.1016/j.celrep.2016.10.053

72. Posnett DN. Environmental and Genetic Factors Shape the Human T-cell Receptor Repertoire. Ann N Y Acad Sci (1995) 756:71-80. doi: 10.1111/j.17496632.1995.tb44483.x

73. Ansari KI, Ogawa D, Rooj AK, Lawler SE, Krichevsky AM, Johnson MD, et al. Glucose-Based Regulation of miR-451/AMPK Signaling Depends on the OCT1 Transcription Factor. Cell Rep (2015) 11:902-9. doi: 10.1016/j.celrep. 2015.04.016

74. Hur W, Lee JH, Kim SW, Kim JH, Bae SH, Kim M, et al. Downregulation of microRNA-451 in Non-Alcoholic Steatohepatitis Inhibits Fatty AcidInduced Proinflammatory Cytokine Production Through the AMPK/AKT Pathway. Int J Biochem Cell Biol (2015) 64:265-76. doi: 10.1016/ j.biocel.2015.04.016

75. Pan X, Wang R, Wang ZX. The Potential Role of miR-451 in Cancer Diagnosis, Prognosis, and Therapy. Mol Cancer Ther (2013) 12:1153-62. doi: 10.1158/1535-7163.MCT-12-0802

76. Song J, Bai Z, Han W, Zhang J, Meng H, Bi J, et al. Identification of Suitable Reference Genes for qPCR Analysis of Serum microRNA in Gastric Cancer Patients. Dig Dis Sci (2012) 57:897-904. doi: 10.1007/s10620-011-1981-7

77. Wang J, Chen J, Sen S. MicroRNA as Biomarkers and Diagnostics. J Cell Physiol (2016) 231:25-30. doi: 10.1002/jcp.25056

78. Sohel MMH. Circulating microRNAs as Biomarkers in Cancer Diagnosis. Life Sci (2020) 248:117473. doi: 10.1016/j.lfs.2020.117473

79. Candido S, Lupo G, Pennisi M, Basile MS, Anfuso CD, Petralia MC, et al. The Analysis of miRNA Expression Profiling Datasets Reveals Inverse microRNA Patterns in Glioblastoma and Alzheimer's Disease. Oncol Rep (2019) 42:91122. doi: 10.3892/or.2019.7215

80. Ceribelli A, Nahid MA, Satoh M, Chan EK. MicroRNAs in Rheumatoid Arthritis. FEBS Lett (2011) 585:3667-74. doi: 10.1016/j.febslet.2011.05.020

81. Randolph HE, Barreiro LB. Herd Immunity: Understanding Covid-19. Immunity (2020) 52:737-41. doi: 10.1016/j.immuni.2020.04.012

82. Luan X, Sansanaphongpricha K, Myers I, Chen H, Yuan H, Sun D. Engineering Exosomes as Refined Biological Nanoplatforms for Drug Delivery. Acta Pharmacologica Sin (2017) 38:754-63. doi: 10.1038/ aps.2017.12

83. de Candia P, Torri A, Gorletta T, Fedeli M, Bulgheroni E, Cheroni C, et al. Intracellular Modulation, Extracellular Disposal and Serum Increase of MiR150 Mark Lymphocyte Activation. PloS One (2013) 8:e75348. doi: 10.1371/ journal.pone.0075348

84. Kowal J, Arras G, Colombo M, Jouve M, Morath JP, Primdal-Bengtson B, et al. Proteomic Comparison Defines Novel Markers to Characterize Heterogeneous Populations of Extracellular Vesicle Subtypes. Proc Natl Acad Sci U S A (2016) 113:E968-77. doi: 10.1073/pnas.1521230113

Conflict of Interest: The author declares that the research was conducted in the absence of any commercial or financial relationships that could be construed as a potential conflict of interest.

Copyright (C) 2021 Oshiumi. This is an open-access article distributed under the terms of the Creative Commons Attribution License (CC BY). The use, distribution or reproduction in other forums is permitted, provided the original author(s) and the copyright owner(s) are credited and that the original publication in this journal is cited, in accordance with accepted academic practice. No use, distribution or reproduction is permitted which does not comply with these terms. 